\title{
Treatment of male urethral strictures - possible reasons for the use of repeated dilatation or internal urethrotomy rather than urethroplasty
}

\author{
C F Heyns, MB ChB, MMed (Urol), PhD, FCSSA (Urol) \\ J van der Merwe, $M B$ ChB, FCUrol (SA) \\ J Basson, $\mathrm{MB} \mathrm{ChB}$ \\ A van der Merwe MB ChB, MRCS, FCUrol (SA), MMed (Urol) \\ Department of Urology, Stellenbosch University and Tygerberg Hospital, Western Cape
}

Objective. To investigate the possible reasons for repeated urethral dilatation or optical internal urethrotomy rather than urethroplasty in the treatment of male urethral strictures.

Patients and methods. Men referred to the stricture clinic of our institution during the period April 2007 - March 2008 were reviewed and the operative urological procedures performed in the same period were analysed. Statistical analysis was performed using Student's $t$-test and Fisher's exact test $(p<0.05$ statistically significant).

Results. The mean age of the 125 men was 49.9 years (range 12.8 - 93.4 years). Previous stricture treatment had been given $1-2,3-4$ and $5-6$ times in $52 \%, 32 \%$ and $12 \%$ of patients, respectively ( $4 \%$ had not undergone treatment). In these groups, previous treatment was dilatation in $70 \%, 76 \%$ and $72 \%$, urethrotomy in $26 \%, 15 \%$ and $28 \%$, and urethroplasty in $4 \%, 9 \%$ and 0 , respectively. The group with 5 - 6 compared with 1 - 2 previous treatments was significantly older (mean age 60.2 v. 46.6 years) and had a significantly greater proportion with underlying co-morbidities $(80 \%$ v. $52 \%)$. The group that had undergone urethroplasty compared with 5 - 6 repeated dilatations or urethrotomies was significantly younger (mean age 48.2 v. 60.2 years) with a lower prevalence of co-morbidities ( $47 \%$ v. $80 \%$ ). During the study period urethroplasty was performed in 16 (2\%) of 821 inpatients, whereas 55 men were seen who had undergone $\geq 3$ previous procedures, indicating that urethroplasty was performed in less than one-third of cases in which it would have been the optimal treatment. Owing to limited theatre time, procedures indicated for malignancy, urolithiasis, renal failure and congenital anomalies were performed more often than urethroplasty.

Conclusions. Factors that possibly influenced the decision to perform repeated urethrotomy or dilatation instead of urethroplasty were limited theatre time, increased patient age and the presence of underlying co-morbidities.

S Afr J Surg 2012;50(3):82-87. DOI:10.7196/SAJS.1081

Urethral dilatation and optical internal urethrotomy are widely used in the treatment of male urethral strictures. In the UK, the treatment for urethral strictures in a general urological setting in the period 1991 - 1999 was urethrotomy in $72 \%$ of cases, dilatation in $26 \%$ and urethroplasty in only $2.4 \%$. In patients with stricture recurrence, the repeat procedures were dilatation in $56 \%$ of cases, urethrotomy in $41 \%$ and urethroplasty in $3.6 \% .{ }^{1}$ Data from the National Health Service in the UK during 2006 showed that the procedures used to treat strictures were urethrotomy or dilatation in $93 \%$ of cases and urethroplasty in only $7 \%{ }^{2}$

A survey among urologists in the USA in 2002 showed that $93 \%$ used dilatation and $86 \%$ optical urethrotomy, whereas $58 \%$ performed urethroplasty for the treatment of urethral strictures. Overall, 35\% performed $1-5$ urethroplasties a year and only $0.7 \%$ performed more than 11 a year., ${ }^{3,4}$ An analysis of Medicare patients in the USA treated for urethral strictures in the period 1992 - 2001 showed that urethrotomy comprised 51 - 58\% of procedures performed, dilatation $35-44 \%$ and urethroplasty only $0.5-0.8 \% .^{5}$ The authors pointed out that if the estimated success rate is $95 \%$ for urethroplasty and $50 \%$ for urethrotomy, the ratio of urethrotomies to urethroplasties performed should be approximately $2: 1$, and if the success rate of urethrotomy is assumed to be $20 \%$, the ratio should 5:4, much lower than the rates of 10:1 and even 50:1 reported in the literature. ${ }^{5}$

Earlier studies suggested that repeated urethrotomy for recurrent urethral strictures may serve to 'stabilise' the stricture, thereby increasing the cumulative success rate. ${ }^{6,7}$ However, since the early 1980s some authors have reported that a second urethrotomy had a lower success rate and that repeated urethrotomy did not improve the cumulative success rate. ${ }^{8,9}$

A prospective randomised study performed at our hospital during the period January 1991 - January 1994 compared filiform dilatation ( $n=106$ patients) with optical urethrotomy $(n=104)$ as treatment for male urethral strictures. ${ }^{10}$ The study compared the stricture recurrence rate among those who had only 1 treatment at study entry, those who had a repeated procedure for stricture recurrence at 3 months, and those who underwent a third treatment for recurrences at 3 and 6 months after initial treatment. In patients not treated before randomisation the estimated stricture-free rate after 1, 2 or 3 repeated treatments was approximately $60 \%, 40 \%$ and $0 \%$ at 24 months, and about $50 \%, 40 \%$ and $0 \%$ at 48 months. After a single dilatation or urethrotomy not followed by re-stricturing at 3 months, the estimated stricture-free rate was $55-60 \%$ at 24 months and 50 $60 \%$ at 48 months. ${ }^{10}$

A study of patients in the UK treated during the period 1991 1999 suggested that a strategy of initial urethrotomy or dilatation 
followed by urethroplasty for recurrent stricture is the most cost-effective strategy. ${ }^{1}$ In contrast, a study from the USA using a cost minimisation decision analysis model for the treatment of a $2 \mathrm{~cm}$ bulbar stricture suggested that urethrotomy was more costly than immediate urethroplasty, unless the estimated longterm success of urethrotomy was greater than $40 \% .{ }^{11}$ A study from the USA considered the costs of treatment as well as lost wages from convalescence and suggested that in the case of a 1 - $2 \mathrm{~cm}$ bulbar urethral stricture the strategy of one urethrotomy before proceeding to urethroplasty was the least costly, unless the expected success rate of urethrotomy was less than $35 \% .^{12}$

It has been suggested that the reasons for utilisation of repeated urethrotomy are lack of urethroplasty expertise among urologists and perverse financial incentives preventing the referral of patients to centres with expertise. ${ }^{13}$ In the USA, physician reimbursement for urethroplasty is approximately twice the amount for urethrotomy, suggesting that there is a financial disincentive to performing urethroplasty. ${ }^{3}$

Despite evidence on the limited usefulness of repeated dilatation and urethrotomy provided by the randomised controlled trial in our hospital, it remains unknown whether this evidence has been applied in practice. The aim of this study was to determine the prevalence of, and possible reasons for, the use of repeated dilatation or urethrotomy rather than urethroplasty in our hospital.

\section{Patients and methods}

Male patients attending the stricture clinic of the general urological service at out institution (a tertiary-level public sector academic teaching hospital serving a largely indigent population without private medical insurance) were interviewed using a structured questionnaire on demographic, socio-economic and clinical aspects of the subject's medical history. Additional information about stricture aetiology and management was obtained from the patient's medical records.

Patients referred to the stricture clinic included all untreated men with a newly diagnosed or suspected urethral stricture, and all men followed up after previous stricture treatment. All patients had been treated at our hospital, and were not referred because of failed stricture treatment elsewhere. Apart from a full history and clinical examination, evaluation included the international prostate symptom score (IPSS), uroflowmetry and ultrasound measurement of the post-void residual. The urethra was evaluated by calibration using Jacques or Nelaton catheters in all patients. Retrograde and/or prograde urethrography and flexible or rigid urethrocystoscopy was performed in patients when the F18 catheter could not be passed. Stricture was defined as a urethral lumen less than F18 in diameter.

Treatment decisions were made in consultation with patients on an individual basis and not according to a rigid protocol. Most of the patients evaluated during the study period had been treated

Table 1. Comparison of clinical findings according to stricture aetiology

\begin{tabular}{|c|c|c|c|c|}
\hline & \multicolumn{4}{|c|}{ Stricture aetiology } \\
\hline & Urethritis & Trauma (external) & Trauma (internal) & Unknown \\
\hline No. & 32 & 19 & 48 & 26 \\
\hline$\%$ & 26 & 15 & 38 & 21 \\
\hline \multicolumn{5}{|l|}{ Age (yrs) } \\
\hline Mean & 46.1 & $36.3^{*}$ & $55.5^{\star}$ & $53.8^{*}$ \\
\hline Range & $23-83$ & $13-61$ & $13-84$ & $31-93$ \\
\hline \multicolumn{5}{|l|}{ Stricture location (\%) } \\
\hline Bulbar & 84 & 68 & 74 & 73 \\
\hline Penile & 34 & 26 & 30 & 46 \\
\hline Membranous & 25 & 32 & 20 & 15 \\
\hline Meatal & 6 & 5 & 15 & 12 \\
\hline \multicolumn{5}{|l|}{ Stricture length } \\
\hline Mean $(\mathrm{cm})$ & 1.5 & 2.3 & 1.8 & 1.1 \\
\hline Range (cm) & $0.5-3$ & $0.5-5$ & $0.5-5$ & $0.5-3$ \\
\hline$<2.1 \mathrm{~cm}(\%)$ & 57.1 & 66.7 & 55 & 53.3 \\
\hline \multicolumn{5}{|l|}{ Previous stricture treatment (\%) } \\
\hline $0-2$ & 69 & 50 & 42 & 56 \\
\hline $3-6$ & 31 & 50 & 58 & 44 \\
\hline \multicolumn{5}{|l|}{ Follow-up (mo.) } \\
\hline Mean & 39.2 & $23.4^{*}$ & 39.7 & 39.9 \\
\hline Range & $3.3-444$ & $0-139.6$ & $0.5-328$ & $3.8-300.4$ \\
\hline Stricture-free at last follow-up (\%) & $75^{\star}$ & 53 & $45^{\star}$ & 54 \\
\hline
\end{tabular}


Table 2. Comparison of clinical findings according to number of previous stricture treatments

\begin{tabular}{|c|c|c|c|}
\hline & \multicolumn{3}{|c|}{ No. of previous stricture treatments } \\
\hline & $1-2$ & $3-4$ & $5-6$ \\
\hline No. & 65 & 40 & 15 \\
\hline$\%$ of total group & 52 & 32 & 12 \\
\hline \multicolumn{4}{|l|}{ Procedure (\%) } \\
\hline Urethral dilatation & 70 & 76 & 72 \\
\hline Internal urethrotomy & 26 & 15 & 28 \\
\hline Urethroplasty & 4 & 9 & 0 \\
\hline \multicolumn{4}{|l|}{ Age (yrs) } \\
\hline Mean & 46.6 & 49.7 & $60.2^{*}$ \\
\hline Range & $21.6-76$ & $12.8-82.7$ & $34.2-84.2$ \\
\hline \multicolumn{4}{|l|}{ Stricture aetiology (\%) } \\
\hline Urethritis & 34 & 18 & 20 \\
\hline Trauma (external) & 17 & 23 & 0 \\
\hline Trauma (internal) & 29 & 40 & 67 \\
\hline Idiopathic & 20 & 20 & 13 \\
\hline Co-morbidities, total (\%) & 52 & 73 & $80^{*}$ \\
\hline \multicolumn{4}{|l|}{ Stricture location (\%) } \\
\hline Bulbar & 79 & 78 & 80 \\
\hline Penile & 34 & 28 & 53 \\
\hline Membranous & 25 & 20 & 13 \\
\hline Meatal & 3 & 18 & 27 \\
\hline \multicolumn{4}{|l|}{ Stricture length } \\
\hline Mean $(\mathrm{cm})$ & 1.3 & 1.7 & 2.2 \\
\hline Range (cm) & $0.5-5$ & $0.5-3$ & $0.5-5$ \\
\hline$<2.1 \mathrm{~cm}(\%)$ & 55 & 59 & 57 \\
\hline \multicolumn{4}{|l|}{ Follow-up (mo.) } \\
\hline Mean & 15.6 & $54.8^{*}$ & $85.4^{*}$ \\
\hline Range & $0.5-83.2$ & $3.3-444.4$ & $11.9-300.4$ \\
\hline Stricture-free at last follow-up (\%) & 65 & 48 & 50 \\
\hline
\end{tabular}

previously by several different urology specialists and residents in our hospital over the course of several years, with no consistent documentation of the reason(s) for specific treatment decisions. Follow-up after treatment was usually scheduled at 3, 6 and 12 months and annually thereafter if no stricture recurrence was found. After every retreatment, follow-up was rescheduled at 3,6 and 12 months and annually thereafter.

The operative procedures performed on inpatients in the main urology theatres during the period of this survey were also analysed to determine the number of urethroplasties performed.

The study protocol for the perusal of medical records was approved by the local institutional review board, and written informed consent for completion of the structured questionnaire was obtained from all study subjects.

All data were entered on an Excel spreadsheet. Statistical analysis was performed using GraphPad Instat software. Student's $t$-test was used for comparison of means and Fisher's exact test for contingency table analysis. A two-tailed $p$-value $<0.05$ was accepted as statistically significant.

\section{Results}

A total of 125 men with proven urethral strictures were evaluated during the period April 2007 - March 2008. The mean patient age was 49.9 years (median 47.7, range 12.8 - 93.4 years). Overall, the mean period between first diagnosis of urethral stricture and last follow-up was 36.9 months (median 14.4, range 0.5 - 444 months).

The causes of the strictures were classified as previous urethritis (infective/inflammatory), external trauma (perineal or straddle injury, pelvic fracture or gunshot wound), internal (iatrogenic) trauma (catheterisation or transurethral resection) and idiopathic (Table 1). Overall, stricture location was bulbar in $76 \%$, penile in $34 \%$, membranous in $22 \%$ and meatal in $10 \%$ (some strictures involved more than one part of the urethra). The stricture was 
Table 3. Comparison of clinical findings in men who underwent urethroplasty versus dilatation or urethrotomy 5 - 6 times

\begin{tabular}{|c|c|c|}
\hline & Urethroplasty & $\begin{array}{l}5-6 \\
\text { dilatations or } \\
\text { urethrotomies }\end{array}$ \\
\hline No. & 15 & 15 \\
\hline \multicolumn{3}{|l|}{ Age (yrs) } \\
\hline Mean & 48.2 & $60.2^{\star}$ \\
\hline Range & $14.4-73.8$ & $34.2-84.2$ \\
\hline \multicolumn{3}{|l|}{ Stricture aetiology (\%) } \\
\hline Urethritis & 13 & 20 \\
\hline Trauma external & 33 & $0^{*}$ \\
\hline Trauma internal & 33 & $67^{*}$ \\
\hline Idiopathic & 20 & 13 \\
\hline \multicolumn{3}{|l|}{$\begin{array}{l}\text { Sexually transmitted } \\
\text { infection (\%) }\end{array}$} \\
\hline $\begin{array}{l}\text { Syphilis serology } \\
\text { positive }\end{array}$ & 7 & 7 \\
\hline HIV serology positive & 8 & 7 \\
\hline Co-morbidities, total (\%) & 47 & $80^{*}$ \\
\hline \multicolumn{3}{|l|}{ Complications (\%) } \\
\hline Retention & 27 & $13^{*}$ \\
\hline Other complications & 33 & 27 \\
\hline \multicolumn{3}{|l|}{ Stricture location (\%) } \\
\hline Bulbar & 86 & 80 \\
\hline Penile & 33 & 53 \\
\hline Membranous & 27 & 13 \\
\hline Meatal & 13 & 27 \\
\hline \multicolumn{3}{|l|}{ Stricture length } \\
\hline Mean $(\mathrm{cm})$ & 2.8 & 2.2 \\
\hline Range $(\mathrm{cm})$ & $1-5$ & $0.5-5$ \\
\hline$<2.1 \mathrm{~cm}(\%)$ & 80 & 57 \\
\hline \multicolumn{3}{|l|}{ Follow-up (mo.) } \\
\hline Mean & 60.4 & $85.4^{\star}$ \\
\hline Range & $4.9-300$ & $11.9-300.4$ \\
\hline $\begin{array}{l}\text { Stricture-free at last } \\
\text { follow-up (\%) }\end{array}$ & 56 & 50 \\
\hline
\end{tabular}

single in $76 \%$ of cases, and the mean stricture length was $1.6 \mathrm{~cm}$ (median 1.0, range $0.5-5 \mathrm{~cm}$ ), the length being $2 \mathrm{~cm}$ or less in $56 \%$ of cases. A comparison of the clinical findings according to stricture aetiology is shown in Table 1.

Overall co-morbidities in the study cohort included hypertension (25\%), previous or current tuberculosis (18\%), renal failure $(11 \%)$, ischaemic heart disease $(9 \%)$, obstructive airway disease $(8 \%)$, erectile dysfunction $(8 \%)$, cancer $(7 \%)$, diabetes mellitus (6\%), epilepsy (4\%), arthritis (4\%), brain damage (3\%) and depression (2\%) (some patients had more than one co-morbidity).
Table 4. Urological procedures performed on inpatients in the main theatre during the study period

\begin{tabular}{lll}
\hline & No. & $\%$ \\
\hline Patients & 821 & \\
Procedures & 1313 & \\
1. Transurethral resection of bladder tumour & 138 & 16.8 \\
2. Prostatectomy (transurethral, open, radical) & 115 & 14.0 \\
3. Nephrectomy, heminephrectomy & 66 & 8.0 \\
4. Orchidopexy & 57 & 6.9 \\
5. Hernia repair (fluid hernia, inguinal hernia) & 56 & 6.8 \\
6. Nephrolithotomy & 51 & 6.2 \\
7. Renal transplantation, Tenckhoff catheter, & 45 & 5.5 \\
arteriovenous fistula & & \\
8. Circumcision & 36 & 4.4 \\
9. Hypospadias repair & 30 & 3.7 \\
10. Bricker diversion, cystectomy & 23 & 2.8 \\
11. Orchidectomy (bilateral or radical) & 21 & 2.6 \\
12. Urethroplasty & 16 & 2.0
\end{tabular}

At the time of evaluation, $4 \%$ of patients had not undergone treatment, and $52 \%$ had undergone $1-2$ and $44 \% 3-6$ previous stricture treatments. The stricture aetiology, co-morbidities and clinical findings were compared according to the number of previous stricture treatments (Table 2). The patient groups with previous urethroplasty and those with $5-6$ previous dilatations or urethrotomies were compared with each other (Table 3 ). Among the patients who had undergone urethroplasty, subsequent dilatation or urethrotomy was performed 1 - 2 times in 53\%, 3 - 4 times in $27 \%$ and not at all in $20 \%$.

During the period April 2007 - March 2008 a total of 831 inpatients underwent a total of 1313 urological procedures in the main operating theatre of our hospital (Table 4).

\section{Discussion}

The current study presents a cross-section of men with a diagnosis of urethral stricture evaluated during the course of a year in the general urological service of a tertiary-level academic hospital. The study cohort probably comprised a selected population, because men who were symptom-free after previous stricture treatment were probably less likely to comply with scheduled follow-up, whereas patients with symptoms due to stricture recurrence were more likely to attend. The results of prior treatment were therefore probably biased towards failed rather than successful treatment.

During the study period there were 55 men who had had 3 or more previous stricture treatments. During the same period, urethroplasty was performed on 16 patients, $2 \%$ of the total number who underwent inpatient urological operations (Table 4). This means that, on average, less than one-third of men who should have had a urethroplasty did in fact undergo the procedure. A previous study showed that during the period $1975-2002$ the average annual number of inpatient operative urological procedures performed in our hospital decreased by a third, largely due to a $35 \%$ reduction in bed numbers and theatre time resulting from budgetary restrictions. ${ }^{14}$ 
Clearly, limited operating time is a major factor in selecting patients for surgery. Whereas urethral stricture disease affects the patient's quality of life and may lead to serious complications, it is rarely life-threatening. The procedures performed more often than urethroplasty in our hospital were mainly indicated for malignancy, urolithiasis, renal failure and congenital anomalies (Table 4). Although repeated dilatation or internal urethrotomy is not optimal treatment, its continued use in our hospital is at least partly determined by selection pressures due to limited operating time. The reasons for the widespread use of repeated dilatation or urethrotomy rather than urethroplasty reported in the USA and the UK remain unknown, because no published studies have directly examined this question. However, limited operating room time due to budgetary constraints is unlikely to be an important reason.

In this study cohort, 3 or more procedures were performed in a greater proportion of men with strictures caused by iatrogenic $(58 \%)$ or external trauma (50\%) than urethritis (31\%). Mean follow-up was significantly shorter in the group with strictures caused by external trauma, possibly because younger men are less likely to return for routine follow-up if asymptomatic. Another possible explanation of the shorter follow-up is that traumatic strictures that recur after treatment do so within a shorter period of time than strictures with other causes (Table 1).

In this study $44 \%$ of the men had undergone $3-6$ previous stricture treatments. Dilatation was the most common form of treatment $(70-76 \%)$, urethrotomy was used less often (15-28\%) and urethroplasty was used least often (4-9\%), and never as a 5 th or 6th procedure (Table 2). Compared with those who had undergone 1 - 2 procedures, the group of men who had undergone 5 - 6 procedures were significantly older ( 60.2 v. 46.6 years), had a greater proportion with iatrogenic strictures (67\% v. $29 \%)$, underlying co-morbidities ( $80 \%$ v. $52 \%)$ and involvement of the penile urethra $(53 \%$ v. $34 \%)$ and meatus $(27 \%$ v. $3 \%)$ rather than the membranous urethra (13\% v. $25 \%)$, and had a greater mean stricture length $(2.2 \mathrm{v} .1 .3 \mathrm{~cm})$ and significantly longer follow-up, but no significant difference was noted with regard to stricturefree rate at last follow-up (50\% v. 65\%) (Table 2).

A recent paper by Santucci and Eisenberg reported that in 136 patients who underwent urethrotomy during the period $1994-2009$ at a centre in the USA the stricture-free rates after $1,2,3,4$ and 5 urethrotomies were $8 \%, 6 \%, 9 \%, 0 \%$ and $0 \%$, respectively, much lower success rates than previously reported. ${ }^{13}$ However, the analysis was based on only 76 (56\%) of the patients who underwent urethrotomy, because the authors excluded 36 patients with complex strictures and 24 who were lost to followup. It is probable that patients lost to follow-up were stricture-free, whereas those with recurrence returned for further treatment. Moreover, the study cohort was probably a highly selected group with stricture recurrence after repeated urethrotomy, referred to a centre with expertise in urethroplasty. ${ }^{13}$

Interestingly, the mean age of the patients in the above study increased with the number of urethrotomies, being 53,57, 61, 68 and 74 years in those who had undergone 1, 2, 3, 4 and 5 previous urethrotomies, respectively. ${ }^{13}$ This indicates that the decision to perform repeated urethrotomy was probably influenced by the patient's age and possibly by other undefined factors. The low success rates of first and second urethrotomy in this study ( $8 \%$ and
$6 \%$ ) are at variance with a large body of evidence in the literature, where the success rates range from $20 \%$ to $80 \%{ }^{15}$

In the current study the use of repeated procedures was associated with significantly increasing patient age and an increasing prevalence of co-morbidities. The significantly longer follow-up in the groups with repeated treatment indicates a greater tendency to stricture recurrence with longer follow-up (Table 3). Presumably many (if not most) patients who remained recurrencefree after initial treatment would not have returned for follow-up. This is the most probable explanation for the similar stricturefree rates at last follow-up, regardless of the number of previous treatments (Table 3).

Factors associated with urethroplasty rather than repeated dilatation or urethrotomy (5 - 6 times) included younger age (48.2 v. 60.2 years), external trauma rather than iatrogenic trauma as aetiology (33\% v. $0 \%$ and $33 \%$ v. $67 \%$, respectively), lower prevalence of co-morbidities ( $47 \%$ v. $80 \%)$, and membranous rather than penile location of the stricture $(27 \% \mathrm{v} .13 \%$ and $33 \%$ v. $53 \%$, respectively) (Table 3 ). The fact that dilatation or urethrotomy was performed 1 - 4 times after urethroplasty in $80 \%$ of these patients indicates selection bias towards men with stricture recurrence after urethroplasty, who were more likely to return for follow-up than those remaining stricture-free. This probably also explains the similar stricture-free rate at last followup after urethroplasty compared with 5 - 6 repeated endoscopic procedures ( $56 \%$ v. $50 \%)$.

This study has some limitations. Although patients were prospectively evaluated during the course of a year, the assessment of previous stricture treatment was retrospective and based on clinical records. Since it was not a prospective follow-up study of all patients who underwent each of the treatment modalities, and because asymptomatic patients were probably less likely to return for long-term routine follow-up, the stricture-free rates found at follow-up do not reflect treatment efficacy, and are probably biased towards treatment failure rather than success. However, the factors determining selection bias were probably the same for all patients, regardless of previous treatment, which confers validity to the comparison of the treatment groups. Unfortunately, the reason(s) for performing repeated dilatation or urethrotomy rather than urethroplasty were not specifically recorded by the treating surgeons, so the reasons for treatment choices can only be inferred from analysis of the data.

\section{Conclusions}

Factors that probably influenced the decision to perform repeated urethrotomy or dilatation instead of urethroplasty in this study were limited theatre time, increased patient age and the presence of underlying co-morbidities, rather than the aetiology or characteristics of the strictures alone.

Source of funding: South African Urological Association.

Conflicts of interest: None.

\section{REFERENCES}

1. Greenwell TJ, Castle C, Andrich DE, et al. Repeat urethrotomy and dilation for the treatment of urethral stricture are neither clinically effective not cost-effective. J Urol 2004;172(1):275-277.

2. Wong SS, Narahari R, O’Riordan A, et al. Simple urethral dilatation, endoscopic urethrotomy, and urethroplasty for urethral stricture disease in adult men. Cochrane Database Syst Rev 2010;(4):CD006934. 
3. Bullock TL, Brandes SB. Adult anterior urethral strictures: a national practice patterns survey of board certified urologists in the United States. J Urol 2007;177(2):685-690

4. Rapp DE, Chanduri K, Infusino G, et al. Internet survey of management trends of urethral strictures. Urol Int 2008;80(3):287-290.

5. Anger JT, Buckley JC, Santucci RA, Elliott SP, Saigal CS and the Urologic Diseases in America Project. Trends in stricture management among male Medicare beneficiaries: underuse of urethroplasty? Urology 2011;77:481-486.

6. Holm-Nielsen A, Schultz A, Møller-Pedersen V. Direct vision internal urethrotomy. A critical review of 365 operations. Br J Urol 1984;56(3):308-312.

7. Albers P, Fichtner J, Brühl P, Müller SC. Long-term results of internal urethrotomy. J Urol 1996;156(5):1611-1614

8. Stone AR, Randall JR, Shorrock K, et al. Optical urethrotomy - a 3-year experience. Br J Urol 1983;55(6):701-704

9. Pansadoro V, Emiliozzi P. Internal urethrotomy in the management of anterior urethral strictures: long-term followup. J Urol 1996;156(1):73-75.
10. Heyns CF, Steenkamp JW, De Kock ML, Whitaker P. Treatment of male urethral strictures: is repeated dilation or internal urethrotomy useful? J Urol 1998;160(2):356-358.

11. Rourke KF, Jordan GH. Primary urethral reconstruction: the cost minimized approach to the bulbous urethral stricture. J Urol 2005;173(4):1206-1210.

12. Wright JL, Wessells $H$, Nathens AB, Hollingworth W. What is the most costeffective treatment for 1 to 2 -cm bulbar urethral strictures: societal approach using decision analysis. Urology 2006;67(5):889-893.

13. Santucci R, Eisenberg L. Urethrotomy has a much lower success rate than previously reported. J Urol 2010;183:1859-1862.

14. Heyns CF, Naudé AM, Pretorius MA. Surgical experience obtained by urology registrars: changes in the volume and spectrum of operative procedures: 1975 2002. African Journal of Urology 2005;11(2):82-88.

15. Naudé AM, Heyns CF. What is the place of internal urethrotomy in the treatment of urethral stricture disease? Nature Clin Pract Urol 2005;2(11):538-545. 